\title{
Numerical Validation of The Influence of Temperature on Viscoelastic Behavior of Silicone Rubber at Low Temperatures
}

\author{
Burak Yenigun $^{1 *}$, E. Gkouti ${ }^{1}$, A. Czekanski ${ }^{\text {*** }}$, K.P. Jankowski ${ }^{2}$ \\ ${ }^{1}$ Department of Mechanical Engineering, York University, Toronto, Canada \\ ${ }^{2}$ Magna Closures of America Inc., Troy, MI, USA \\ *byenigun@yorku.ca, **alex.czekanski@lassonde.yorku.ca
}

\begin{abstract}
This study aims to model and validate the influence of temperature on the stress relaxation of silicone rubber, numerically. The stress relaxation tests were performed at a constant strain level using a constant crosshead speed at the below ambient temperatures. The Time-Temperature superposition, The Williams-Landed-Ferry (WLF), was applied to describe temperature and stress relaxation of Silicone rubber. First, the master curve was obtained, and then the WLF coefficients were determined by curve fitting technique. This study demonstrated that temperature affected the stress relaxation and stress relaxation decreases with decreasing temperature. Also, FEM results validated the experimental results.
\end{abstract}

\section{Keywords; Stress Relaxation; Silicon Rubber; WLF}

\section{INTRODUCTION}

Elastomers are key materials which used in many different industrial applications, including military, food, medicine, automotive industries, where heat resistance, chemical stability, electrical insulation, and abrasion resistance are critical [1]. Time-dependent mechanical properties of elastomers titled as viscoelasticity, especially it is very critical for the application of sealants, gaskets [2]. Stress relaxation is one technique to demonstrate the viscoelastic behaviour of elastomers. An instant load is applied to elastomers to reach a certain level of strain level. Afterward, the load is removed suddenly, and it is held at a constant strain level. Stress decreases over time, and this time-dependent decrease demonstrates the stress relaxation of the elastomers. One of the most critical parameters affecting stress relaxation is temperature [3]. Williams-Landel-Ferry (WLF) technique is the one method to determine the temperature-dependent of the viscoelastic properties of elastomers [4]. WLF is the default shift function in Abaqus. However, the researchers mostly researched the viscoelastic behaviour of elastomers at constant temperatures [5-6]. This paper aims to model and validate the influence of temperature on the stress relaxation of silicone rubber using FEM. The stress relaxation tests of silicone rubber were performed under strain level of $\% 100$ at $-40^{\circ} \mathrm{C},-20^{\circ} \mathrm{C}, 0^{\circ} \mathrm{C}$, and $20^{\circ} \mathrm{C}$ temperatures. Afterward, Shift factors for each temperature were determined. Then WLF coefficients were obtained by curve fitting method using Matlab Curve Fitting Tool. Finally, stress relaxation tests were simulated in the Abaqus.

\section{MATERIAL AND METHODS}

\section{A. Material}

The high-temperature silicone rubbers are used in the experiments has been supplied from Mcmaster company. Silicone rubber was cut into $150 \mathrm{~mm} \times 100 \mathrm{~mm} \times 1.5875 \mathrm{~mm}$ sizes to make it suitable for the planar test. The mechanical properties of silicone rubber are given in Table 1 .

Table 1. Mechanical Properties of Silicon Rubber

\begin{tabular}{|c|c|c|c|c|}
\hline $\begin{array}{c}\text { Thickness } \\
\text { (mm) }\end{array}$ & $\begin{array}{c}\text { Temperature Range } \\
\left.\text { ( }{ }^{\circ} \mathbf{C}\right)\end{array}$ & $\begin{array}{c}\text { Tensile Strength } \\
\text { (MPa) }\end{array}$ & Durometer & $\begin{array}{c}\text { Brittle Point } \\
\left({ }^{\circ} \mathbf{C}\right)\end{array}$ \\
\hline 1.5875 & -62 to 260 & 5.86 & $40 \mathrm{~A}$ & -62.2 \\
\hline
\end{tabular}

\section{B. Relaxation Tests}

The Relaxation tests of Silicone rubbers were performed using a universal tensile testing machine at a constant strain level $\% 100$ and at $-40^{\circ} \mathrm{C},-20^{\circ} \mathrm{C}, 0^{\circ} \mathrm{C}$, and $20^{\circ} \mathrm{C}$ temperatures. The relaxation time was determined as 900 s according to the pre-test. The strains were measured by laser extensometer during the tests. The experimental setup is shown in Fig. 1.

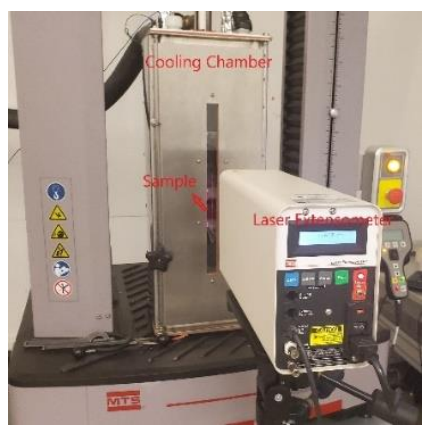

Figure 1. The experimental Setup 


\section{C. $W L F$}

The WLF equation presented by Williams, Landel, and Ferry is a technique for demonstrates the viscoelastic behavior of elastomers at elevated temperatures based on shifting temperature. [7]. In order to relate relaxation modulus at different temperatures (in Fig. 2.), the WLF equation introduces a time shift factor (1), a .

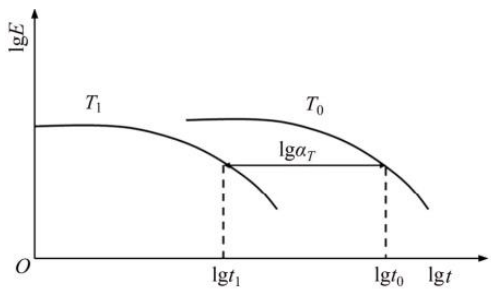

Figure 2. Time-Temperature Superposition Principle [8]

The shift factor is defined as the ratio between the time for test temperature and time for the reference temperature. The WLF equation is as follows:

$$
\log \left(a_{T}\right)=-\frac{C_{1} *\left(T_{1}-T_{0}\right)}{C_{2}+\left(T_{1}-T_{0}\right)}
$$

Where, $C_{1}, C_{2}, a_{T}, T_{1}$ and $T_{0}$ are constant 1 , constant 2 , shift factor, test temperature, and reference temperature, respectively.

\section{RESULTS}

\section{A. Stress Relaxation}

Stress relaxation of silicone rubber under $\% 100$ strain level at temperatures of $-40^{\circ} \mathrm{C},-20^{\circ} \mathrm{C}, 0{ }^{\circ} \mathrm{C}$, and $20^{\circ} \mathrm{C}$ is shown in Fig. 3. Relaxation modulus decreases with the increase of temperature.

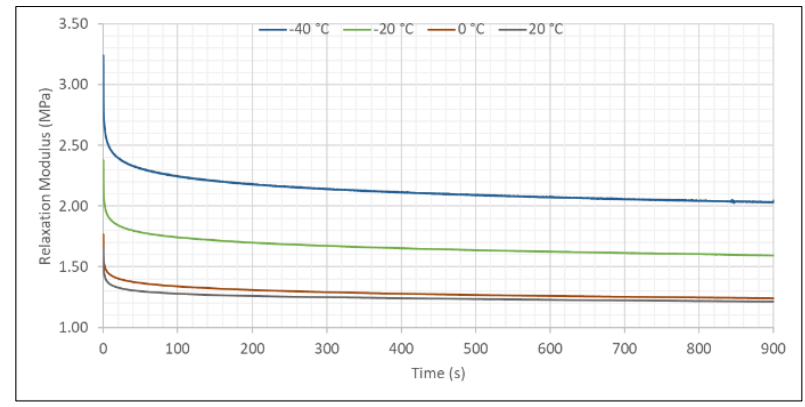

Figure 3. Stress Relaxation of Silicon Rubber at Different Temperature.

Relaxation modulus should be converted to normalized stress data to simulate relaxation in Abaqus, [9]. The normalized stress relaxation of silicone rubber under $\% 100$ strain at the temperature of $-40^{\circ} \mathrm{C},-20^{\circ} \mathrm{C}, 0{ }^{\circ} \mathrm{C}$, and $20^{\circ} \mathrm{C}$ is shown in Fig. 4. Stress relaxes quickly at the beginning then reach the equilibrium. Also, the stress relaxes more quickly under a lower temperature condition.

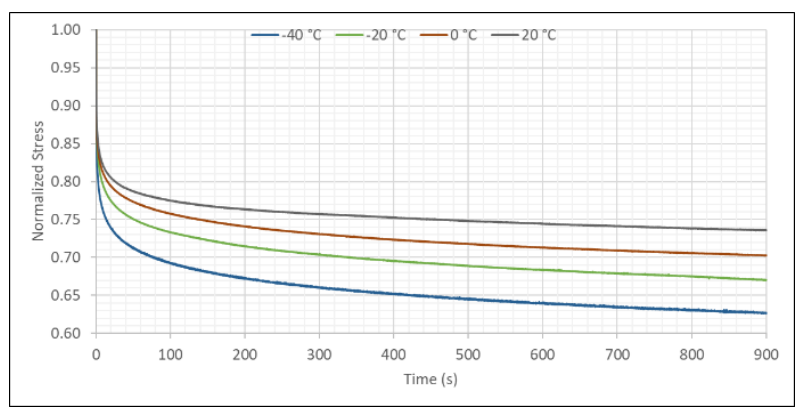

Figure 4. Normalized Stress Relaxation of Silicon Rubber

\section{B. $W L F$}

The essential things in this technique are to obtain the master curve correctly and to determine the WLF coefficients. The experimental and fitted shift factor of silicone rubber with reference $-40^{\circ} \mathrm{C}$ are shown in Fig. 5. The shift factor was obtained at a high correlation rate, $\mathrm{R}^{2}=0.9992$ The reference temperature was selected as $-40^{\circ} \mathrm{C}$. Therefore, the shift factor is decreased with a decrease in temperature.

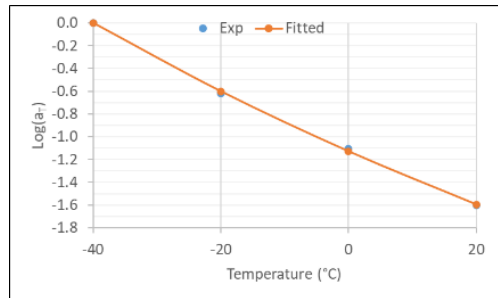

Figure 5. Shift Factor of Silicone Rubber with Reference $-40^{\circ} \mathrm{C}$

$C_{1}, C_{2}$ WLF coefficients were found as -9.23 and 287.6 by Matlab Curve Fitting Toolbox. The master curve relaxation modulus of silicone rubber at the reference temperature, $-40^{\circ} \mathrm{C}$, is shown in Fig. 6.

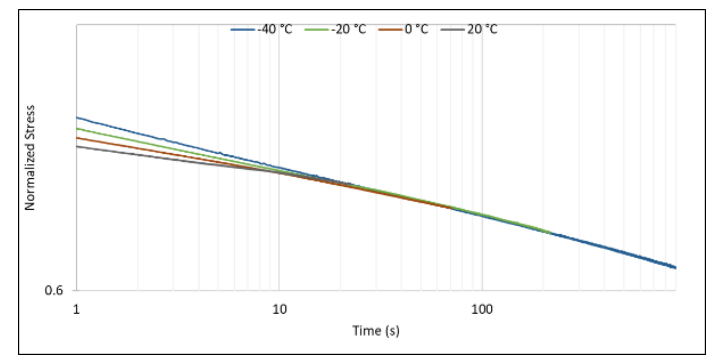

Figure 6. Master Curve of Normalized Stress Relaxation at $-40^{\circ} \mathrm{C}$

C. FEM

The comparison of experimental and FEM results are shown in Fig. 7. It can be seen that the FEM results obtained were close to experimental results. 


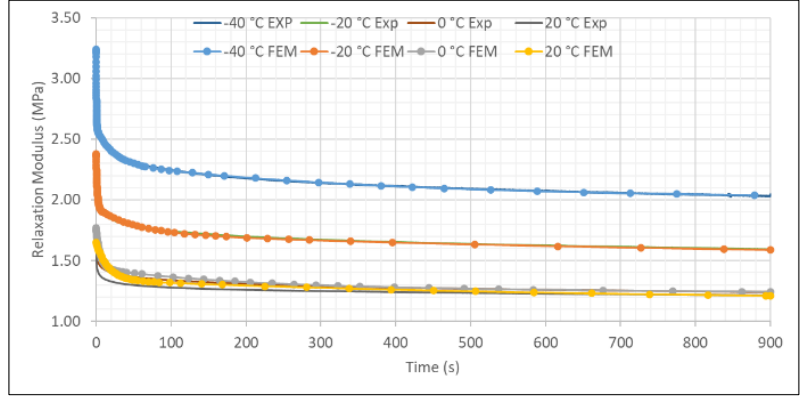

Figure 7. Fem Results a) $-40^{\circ} \mathrm{C}$, b) $-20^{\circ} \mathrm{C}, 0^{\circ} \mathrm{C}, 20^{\circ} \mathrm{C}$

\section{CONCLUSIONS}

In this study, the influence of temperature on stress relaxation of silicone rubber was investigated. The results of this study show that;

The temperature had a critical influence on the stress relaxation.

$>$ The relaxation modulus decreased with the increased temperature.

The numerical validation of relaxation tests was performed at high correlations.

\section{REFERENCES}

[1] W. Wu and H. Huang, "Silicone rubber composites fabricated using KH550-modified poplar leaves graphene," Bull. Mater. Sci., vol. 43, no. 1, 2020.

[2] Anshuman Shrivastava, Introduction to Plastics Engineering. 2018.

[3] M. Abu-Abdeen, "The unusual effect of temperature on stress relaxation and mechanical creep of polycarbonate at low strain and stress levels," Mater. Des., vol. 34, pp. 469-473, 2012.

[4] T. Cui, Y. J. Chao, and J. W. Van Zee, "Thermal stress development of liquid silicone rubber seal under temperature cycling," Polym. Test., vol. 32, no. 7, pp. 1202-1208, 2013.

[5] S. Ronan, T. Alshuth, S. Jerrams, and N. Murphy, "Long-term stress relaxation prediction for elastomers using the time-temperature superposition method," Mater. Des., vol. 28, no. 5, pp. 1513-1523, 2007.

[6] D. Liu, M. A. Hickner, S. W. Case, and J. J. Lesko, "Relaxation of proton conductivity and stress in proton exchange membranes under strain," J. Eng. Mater. Technol. Trans. ASME, 2006.

[7] M. L. Williams, R. F. Landel, and J. D. Ferry, "The Temperature Dependence of Relaxation Mechanisms in Amorphous Polymers and Other Glass-forming Liquids," J. Am. Chem. Soc., 1955.

[8] G. Li, J. Ming Gong, J. zhu Tan, D. Sheng Zhu, and W. Hua Jia, "Stress relaxation behavior and life prediction of gasket materials used in proton exchange membrane fuel cells," J. Cent. South Univ., vol. 26, no. 3, pp. 623-631, 2019.

[9] 2014 Dassault Systèmes, “Abaqus/CAE User's Guide.” [Online]. Available: http://ivtabaqusdoc.ivt.ntnu.no:2080/v6.14/books/usi/default.htm. [Accessed: 01-Mar-2020]. 